Article

\title{
Tree Crown Mapping in Managed Woodlands (Parklands) of Semi-Arid West Africa Using WorldView-2 Imagery and Geographic Object Based Image Analysis
}

\author{
Martin Karlson ${ }^{1, *}$, Heather Reese ${ }^{2, \dagger}$ and Madelene Ostwald ${ }^{1,3, \uparrow}$ \\ 1 Centre for Climate Science and Policy Research, Department of Thematic Studies/Environmental \\ Change, Linköping University, Linköping 58183, Sweden; E-Mail: madelene.ostwald@chalmers.se \\ 2 Section of Forest Remote Sensing, Department of Forest Resource Management, \\ Swedish University of Agricultural Sciences, Umeå 901 83, Sweden; E-Mail: heather.reese@slu.se \\ 3 Centre for Environment and Sustainability, GMV, University of Gothenburg and \\ Chalmers University of Technology, Göteborg 405 30, Sweden
}

$\dagger$ These authors contributed equally to this work.

* Author to whom correspondence should be addressed; E-Mail: martin.karlson@liu.se; Tel.: +46-1328-2977; Fax: +46-1313-3630.

External Editor: Assefa M. Melesse

Received: 27 August 2014; in revised form: 13 November 2014 / Accepted: 19 November 2014 / Published: 28 November 2014

Abstract: Detailed information on tree cover structure is critical for research and
monitoring programs targeting African woodlands, including agroforestry parklands. High
spatial resolution satellite imagery represents a potentially effective alternative to
field-based surveys, but requires the development of accurate methods to automate
information extraction. This study presents a method for tree crown mapping based on
Geographic Object Based Image Analysis (GEOBIA) that use spectral and geometric
information to detect and delineate individual tree crowns and crown clusters. The method
was implemented on a WorldView- 2 image acquired over the parklands of Saponé,
Burkina Faso, and rigorously evaluated against field reference data. The overall detection
rate was $85.4 \%$ for individual tree crowns and crown clusters, with lower accuracies in
areas with high tree density and dense understory vegetation. The overall delineation error
(expressed as the difference between area of delineated object and crown area measured in
the field) was $45.6 \%$ for individual tree crowns and $61.5 \%$ for crown clusters. Delineation 
accuracies were higher for medium $\left(35-100 \mathrm{~m}^{2}\right)$ and large $\left(\geq 100 \mathrm{~m}^{2}\right)$ trees compared to small $\left(<35 \mathrm{~m}^{2}\right)$ trees. The results indicate potential of GEOBIA and WorldView-2 imagery for tree crown mapping in parkland landscapes and similar woodland areas.

Keywords: remote sensing; high spatial resolution; WorldView-2; tree crown mapping; tree crown delineation; geographic object based image analysis; woodland; agroforestry; parkland; Burkina Faso

\section{Introduction}

With a spatial extent of close to 9 million $\mathrm{km}^{2}[1,2]$, woodland is the most extensive vegetation type in Africa (Figure 1). Since approximately $60 \%$ of the woodland area in Africa is under cultivation [3], this vegetation type represents the subsistence base for the majority of the rapidly growing population [4,5]. In semi-arid West Africa, small scale shifting cultivation in traditional agroforestry systems constitutes the main agricultural practice [6,7]. Such modified and managed woodland landscapes are locally referred to as parklands [6,8]. Discontinuous tree cover is a critical component of the parklands [6,9] as it controls a number of key ecosystem service functions (e.g., microclimate and soil properties, including soil water dynamics and carbon sequestration) and provides important subsistence resources (e.g., food, fodder, medicine and fire wood). Recently, concerns have been raised that changing climatic conditions are causing tree cover degradation (with diminishing tree densities and altered species composition) in this region [10-12]. A strong increase in population, and demand for agricultural land, tree products and grazing land also exert pressure on the tree cover and constrain tree regeneration [13-15]. At present, a general shortage of tree cover data impairs the preconditions for scientifically sound research and monitoring needed for informed management decisions in parkland and other African woodland areas [1,16]. Since detailed field based tree inventories are highly labor- and cost-intensive, and problematic to conduct on broad scales, alternative approaches to tree cover data collection are needed.

\subsection{Mapping Tree Cover with High Spatial Resolution Satellite Imagery}

Remote sensing has become a key tool for broad scale analysis of forest and woodland ecosystems. The improved level of detail from high spatial resolution (HSR; $\leq 4 \mathrm{~m}$ ) satellite imagery has expanded the possibilities to map structural and floristic attributes of forest stands, as well as individual trees [17-19]. Accurate detection and delineation of individual tree crowns (ITC) in HSR imagery is a critical step for remote sensing based tree inventories because it generates the basic unit of measurement upon which other structural and demographic attributes are based [20], including crown area $\left(\mathrm{CA} ; \mathrm{m}^{2}\right)$, tree density (TD; trees/ha) and tree canopy cover (\%). Mapping the distribution of ITC across large areas holds potential for a wide range of research and management applications. For example, tree crown size (area, radius or diameter) has been used to model structural attributes, such as basal area, diameter at breast height $(\mathrm{DBH})$ and above ground biomass through allometric relationships [21-23]. Tree crown delineation is also a key step in remote sensing based tree species discrimination [24], and for 
spectral assessments of tree cover condition, for example water stress [25], because its accuracy controls the quality of the extracted reflectance spectra $[20,26]$. It is noteworthy that numerous studies have reported significantly higher accuracies when tree species classification is performed on the crown level as compared to pixel-level approaches, e.g., [26-29].

Figure 1. (a) Distribution of woodlands in Africa and location of study site (source: modified from White [2]); (b) WorldView-2 image of the study area and location of field plots.

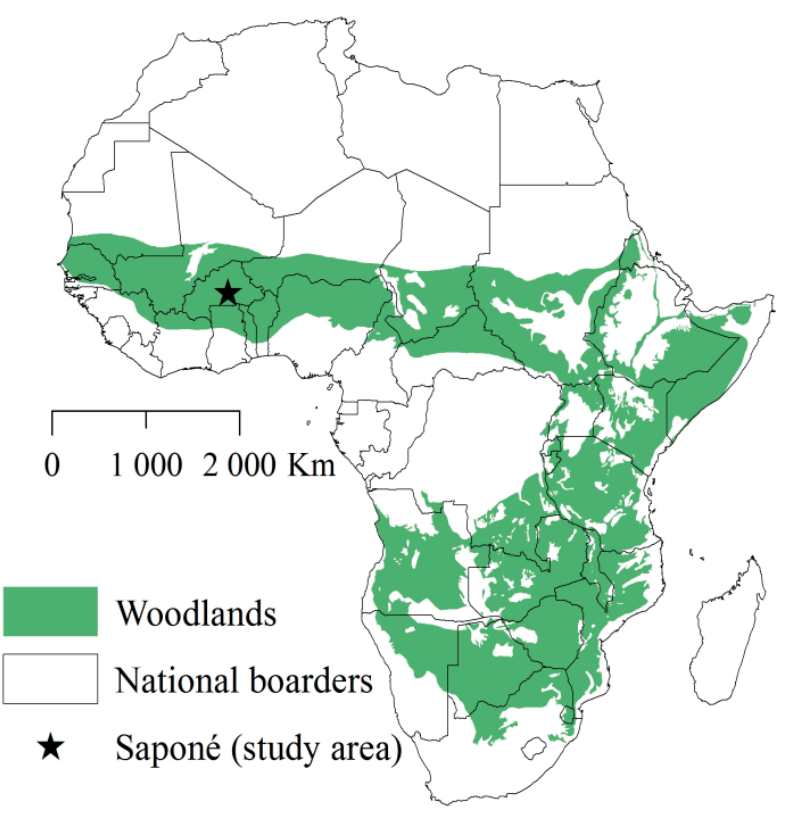

(a)

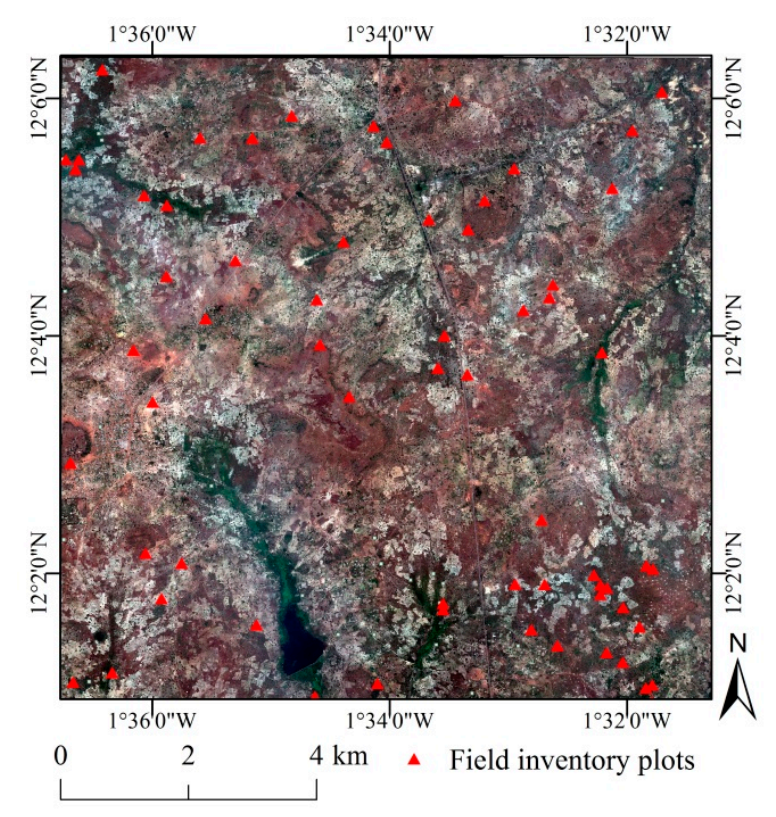

(b)

For detailed tree cover mapping, HSR satellite imagery constitute an economically and practically feasible alternative to airborne systems, such as hyper-spectral imagers and Light Detection and Ranging (LiDAR), as access and resources for these are often limited in Africa [28,30]. A range of commercially operated satellite systems (e.g., Quickbird, OrbView, WorldView and GeoEye) now provide, on request, global coverage of panchromatic and multispectral imagery at high spatial resolution, enabling analysis on the ITC scale [31-34]. While such HSR imagery has been successfully used for inventories of high latitude conifer forests [17-19,34], its applicability in tropical ecosystems has received limited scientific attention [35-37].

\subsection{Techniques to Detect and Delineate Tree Crowns in HSR Imagery}

Many methods to automate tree crown detection and delineation in HSR imagery have been developed over the years. Tree crown detection has commonly used techniques based on local maxima filtering [38], adaptive binarization [39] and template matching [40]. Tree crown delineation has been realized through different types of segmentation algorithms, including region-growing [41], valley-following [42] and watershed segmentation [43]. Common for all these approaches is that they use the same basic assumption for pattern recognition: that the geometric centers of illuminated crowns (tree tops) appear brighter than crown edges in HSR imagery (see e.g., [34,41,44]). Research on 
automated tree crown detection and delineation has primarily been conducted in North America and Northern Europe, targeting applications in managed coniferous forests often characterized by a relatively homogeneous structure with uniform tree sizes, age classes, spacing, species compositions, crown shapes, and a contrasting field layer. Such a tree cover structure translates to relatively consistent radiometric patterns in HSR imagery, facilitating the implementation of automated methods [45]. Consequently, the majority of automated tree crown mapping methods are less applicable in areas where the tree cover is structurally complex and where deciduous tree species dominate $[20,44]$. Such complex tree cover conditions are found across large parts of the African woodlands, including the parkland-landscapes of West Africa.

Five main factors introduce complexity to the spectral response of parkland tree cover that complicate automated crown mapping in HSR imagery [41,44]: (1) trees often have similar leaf area index (LAI) to that of shrubs and herbaceous vegetation, making separation based on spectral information difficult [46,47]; (2) the field layer is often heterogeneous in terms of soil color and vegetation density due to local topographic and edaphic conditions and land use; (3) local environmental conditions and land use also introduce large variations in the tree cover structure, including highly variable trees sizes, densities and spacing; (4) deciduous tree species generally support a structurally complex crown that causes high within-crown brightness variations in HSR imagery due to the heterogeneous reflectance of branches and related shadows; and, (5) the spectral variation within and between tree species may be high due to differences in leaf reflectance properties (e.g., foliar biochemistry, moisture content and structure) resulting from local environmental conditions, phenological variations and evolutionary adaptation traits of semi-arid vegetation [44].

\subsection{Moving from Pixel-Level to Object-Level Information}

The previously mentioned factors indicate that the spectral content of individual pixels is not sufficiently consistent for accurately characterizing parkland tree cover in HSR imagery. To overcome these problems, spatial information in HSR imagery, including geometry (e.g., shape and size), texture and context, can be exploited when designing algorithms for tree crown delineation $[41,43,48]$. Geographic object based image analysis (GEOBIA) has been proposed as a suitable approach for a wide variety of complex feature recognition problems in remote sensing [49], including tree crown delineation $[21,44,49]$. Within GEOBIA, regions of spectrally similar and spatially connected pixels (objects) form the units for data processing, instead of individual pixels. The image objects that are generated by image segmentation techniques contain geometric, textural, contextual, as well as spectral information [50,51]. From a theoretical perspective, GEOBIA appears to be a well-suited approach for automated tree crown delineation in parkland landscapes for several reasons. In particular, GEOBIA facilitates feature recognition at multiple spatial scales [52]. This means that crown delineation algorithms can be adapted to handle both groups of trees and individual trees despite large size variations. GEOBIA is also suitable to counter the H-resolution problem [51,53] of high within-class spectral variability inherent to HSR imagery in general, and areas of heterogeneous tree cover in particular. GEOBIA can thus improve mapping accuracy and reduce effects of "salt-and-pepper" speckle, which is a common problem in pixel based analysis. 
Previous research suggests that the information within objects is highly useful for separating different vegetation types with similar spectral signatures [54] and for detection and delineation of tree crowns in complex environments [44,49]. While the GEOBIA approach has shown promise in African woodland landscapes for satellite based mapping of aggregated tree cover variables, such as tree canopy cover [21,55], its use for the delineation of ITC has not been extensively evaluated in the tropics [34]. An exception to this was provided by Bunting and Lucas who applied a rule-based GEOBIA approach to delineate ITC and crown clusters in an Australian woodland area (Queensland) using hyper-spectral imagery from the Compact Airborne Spectrographic Imager (44).

\subsection{Research Objectives}

The research presented in this article has two objectives: (1) develop a tree crown delineation method for application with HSR satellite imagery in African parkland landscapes using GEOBIA; and (2) conduct a detailed accuracy assessment of the tree crown delineation method using field reference data.

The article addresses the following question: how effective is the combination of GEOBIA and HSR satellite imagery for automating tree crown delineation in a parkland landscape? This is assessed in terms of: (i) the degree of agreement between reference trees, including their crown area, and tree crowns delineated by the automated method; and (ii) the overall correspondence between plot level tree canopy cover (i.e., aggregated crown area) derived from the reference trees and the delineated trees. We will also analyze the types of errors (e.g., omission and commission errors) and the potential causes (e.g., crown dimension, tree species and land use).

\section{Study Area and Data}

\subsection{Geographical Background}

The $10 \mathrm{~km} \times 10 \mathrm{~km}$ study site is located on a low relief plain (293-363 m above sea level) $35 \mathrm{~km}$ south of Ouagadougou within the rural commune of Saponé (Bazega province; 1204'48" N, $\left.1^{\circ} 34^{\prime} 00^{\prime \prime} \mathrm{W}\right)$. The local climate is bimodal with a rainy season taking place between April and October, followed by a long dry spell. Annual mean rainfall is approximately $790 \mathrm{~mm} \cdot \mathrm{year}^{-1}$ (1952-2010) and the annual levels range between 570 and $1180 \mathrm{~mm} \cdot \mathrm{year}^{-1}$, with about $80 \%$ of the rainfall falling during June through September (Direction de la Météorologie du Burkina Faso). The mean annual temperature (1952-2008) is $28{ }^{\circ} \mathrm{C}$ and the mean annual potential evapotranspiration is $1900 \mathrm{~mm} \cdot$ year $^{-1}$ (1974-2003), which means that the climate is semi-arid according to the Köppen-Geiger climate classification system [56]. The soils of the area are sandy loamy Regoslos with low nutrient content [57]. Biogeographically, Saponé is located in the Sudano-Sahelian ecotone [58].

The landscape of the study site consists of a mosaic of settlements, active and fallowed rain-fed farm land (i.e., parklands), scattered tree plantations and patches of dense woodland (e.g., riparian formations). The parklands are dominated by the traditional agroforestry tree species Vitellaria paradoxa, Parkia biglobosa and Lannea microcarpa, and used for cultivation of staple crops, such as millet, sorghum (red and white) and maize, together with legumes (e.g., cow pea and peanut). Other well known agroforestry tree species found in the area include Adansonia digitata, Faidherbia albida 
and Bombax costatum, Vitellaria paradoxa and Parkia biglobosa are generally considered deciduous but are rarely leafless because of a progressive replacement of the leaves [6]. Lannea species (microcarpa and acida), Adansonia digitata and Bombax costatum, on the other hand, shed leaves in the dry season [59]. Faidherbia albida has a reverse phenology: it foliates during the start of the dry season and sheds leaves early in the wet season. The fields are regularly fallowed for 3-5 years. In comparison to active fields, the fallows are characterized by a higher tree density and species diversity, and a denser understory composed of annual grasses, shrubs and tree re-growth (Figure 2).

Figure 2. Picture showing examples of (a) active field (b) and fallow dominated by Vitellaria paradoxa.

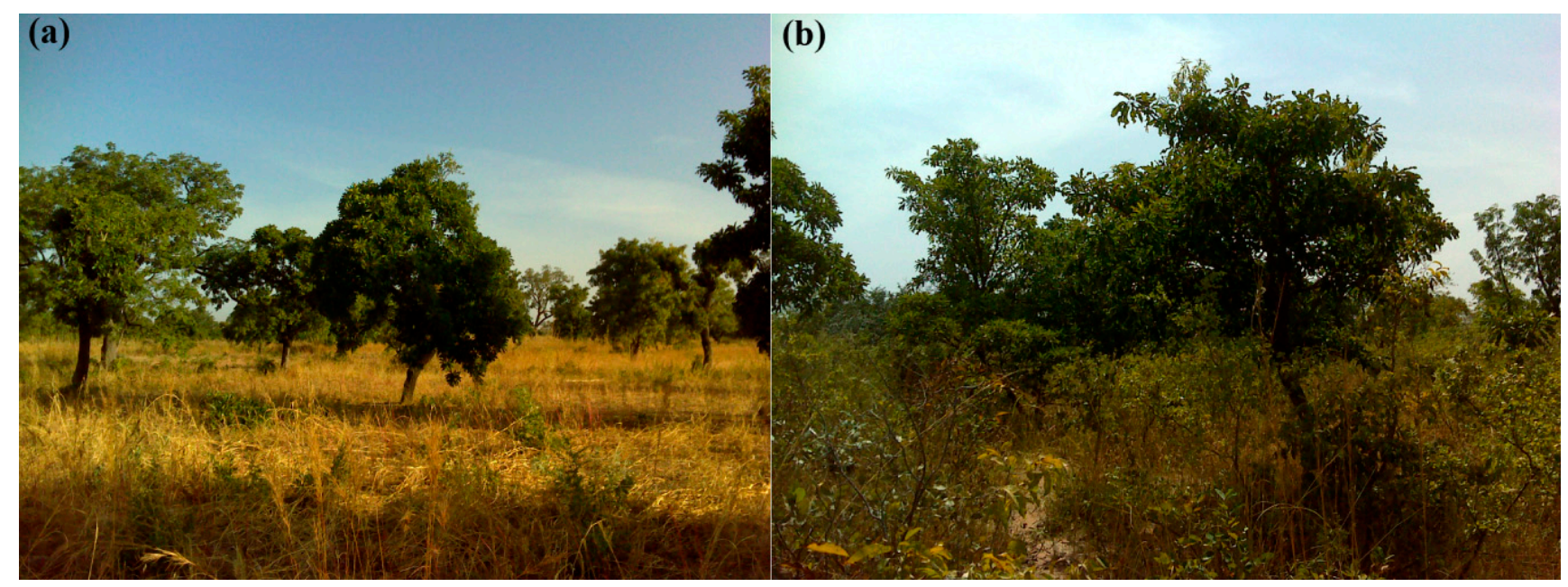

\subsection{Satellite Data and Preprocessing}

A WorldView-2 image was acquired under cloudless conditions on 21 October 2012 (processing level: Ortho Ready Standard, scan direction: forward). This date represents the early dry season when most of the tree species have fully developed foliage. The WorldView-2 satellite provides data in one panchromatic band and 8 spectral bands (Table 1.). The ground sampling distance at nadir is $0.5 \mathrm{~m}$ for the panchromatic band and $2 \mathrm{~m}$ for the multispectral bands.

Table 1. Technical specifications of the WorldView-2 image acquired 21 October 2012 (Source: Digital Globe 2013a).

\begin{tabular}{ccccc}
\hline Band & Wavelength Region $(\boldsymbol{\mu m})$ & Pixel Size $(\mathbf{m})$ & & \\
\hline Panchromatic & $0.450-0.800$ & 0.5 & Acquisition date & 21 October 2012 \\
Coastal blue & $0.400-0.450$ & 2 & Acquisition time & $13: 55: 15$ \\
Blue & $0.450-0.510$ & 2 & Mean off-nadir angle & $12.9^{\circ}$ \\
Green & $0.510-0.580$ & 2 & Mean sun azimuth & $153.4^{\circ}$ \\
Yellow & $0.585-0.625$ & 2 & Mean sun elevation & $64.5^{\circ}$ \\
Red & $0.630-0.690$ & 2 & Mean satellite azimuth & $192.4^{\circ}$ \\
Red edge & $0.705-0.745$ & 2 & Mean satellite elevation & $75.3^{\circ}$ \\
NIR 1 & $0.770-0.895$ & 2 & & \\
NIR 2 & $0.860-1.040$ & 2 & & \\
\hline
\end{tabular}


Digital numbers of the nine bands were converted to top-of-atmosphere radiance using the embedded absolute radiometric calibration factors and effective bandwidths, according to the specifications provided in [60]. The Hyperspherical Color Space (HCS) algorithm [61] and a $7 \times 7$ pixel smoothing filter was used to fuse the multispectral bands with the panchromatic band, resulting in an 8-band pan-sharpened image with a pixel size of $0.25 \mathrm{~m}^{2}$. The HCS algorithm was developed specifically for use with WorldView-2 data and implemented in ERDAS Imagine 2013 software. The pan-sharpened image was rectified to UTM $30 \mathrm{~N}$ using 35 ground control points collected in the field and third order polynomials, with a root mean square error (RMSE) of less than one pixel. The satellite data served two purposes in this study: (i) to support the establishment of field inventory plots; and (ii) to map tree crowns using GEOBIA.

\subsection{Field Reference Data}

A field inventory was conducted in November 2012 where a total of 64 square inventory plots $(50 \mathrm{~m} \times 50 \mathrm{~m})$ were collected. Field data collection followed a stratified random sampling procedure in order to ensure coverage of the different tree densities in the study area. The stratification was achieved by partitioning the study areas into four classes of tree canopy cover (CC; Table 2) using the Normalized Difference Vegetation Index (NDVI) data [62] derived from the WorldView-2 image and a moving window approach [63]. Samples were not taken from the first strata $(0 \% \mathrm{CC})$ since these were areas without trees (validated in the field campaign). Even though the stratification was based on a rather crude estimation of tree canopy cover, it captured the characteristics of the study site well. An approximately even number of plots per strata with $\mathrm{CC}>0$ were randomly distributed throughout the parklands of the study area.

Table 2. Characteristics of the stratification used during field work, including tree canopy cover (CC), tree density (TD), standard deviation (s.d.) and distribution of field plots.

\begin{tabular}{ccccccccc}
\hline Strata & $\begin{array}{c}\mathbf{C C} \\
\mathbf{( \% )}\end{array}$ & $\begin{array}{c}\mathbf{T D}^{\mathrm{ha}-\mathbf{1}} \\
\mathbf{M i n}\end{array}$ & $\begin{array}{c}\mathbf{T D}^{\mathrm{ha}-\mathbf{1}} \\
\mathbf{M a x}\end{array}$ & $\begin{array}{c}\mathbf{T D}^{\mathrm{ha}-\mathbf{1}} \\
\text { Average }\end{array}$ & $\begin{array}{c}\mathbf{T D}^{\text {ha }-\mathbf{1}} \\
\text { s.d. }\end{array}$ & $\begin{array}{c}\text { Plots } \\
\text { Total }\end{array}$ & $\begin{array}{c}\text { Plots in } \\
\text { Active Field }\end{array}$ & $\begin{array}{c}\text { Plots in } \\
\text { Fallow }\end{array}$ \\
\hline 1 & 0 & - & - & - & - & - & - & - \\
2 & $\geq 0-10$ & 4 & 56 & 21 & 14 & 24 & 16 & 8 \\
3 & $\geq 10-40$ & 8 & 64 & 32.5 & 14.6 & 23 & 10 & 13 \\
4 & $\geq 40$ & 24 & 208 & 96.4 & 54.4 & 18 & 4 & 14 \\
Total & & 4 & 208 & 46.6 & 44.5 & 64 & 29 & 35 \\
\hline
\end{tabular}

Plot centers were located in the field using a Global Positioning System (GPS; Garmin Oregon 550, Garmin, Olathe, KS, USA) receiver and printed true-color composite maps of the study area. For each plot the current land use was noted. Trees with a $\mathrm{DBH} \geq 5 \mathrm{~cm}$ were surveyed for the variables listed in Table 3. Ground projected crown area (CA) was calculated by assuming an elliptical crown shape using Equation (1) [64]. In order to account for the positional uncertainties related to the GPS recordings, each point was manually related to a tree in the image using information on crown dimensions, height and species as guidance. 


$$
\mathrm{CA}=\pi\left(\frac{\mathrm{D} 1}{2} \times \frac{\mathrm{D} 2}{2}\right)
$$

Table 3. Data collected for each tree during fieldwork.

\begin{tabular}{ll}
\hline Surveyed Variables & Comment \\
\hline Tree ID & Unique identifier \\
Location & X,Y using GPS (Garmin Oregon 550) \\
Species & Identified by local botanist \\
DBH $(\mathrm{cm})$ & Tree stem diameter measured at $1.3 \mathrm{~m}$ above ground \\
Tree height $(\mathrm{m})$ & Haglof Electronic Clinometer \\
Crown diameter $(\mathrm{D} 1 ; \mathrm{m})$ & Below crown distance measurements of the largest axis using tape measure \\
Crown diameter $(\mathrm{D} 2 ; \mathrm{m})$ & Below crown distance measurements of the axis perpendicular to D1 \\
\hline
\end{tabular}

A total of 36 tree species were identified during the field inventory. The four most abundant tree species (Vitellaria paradoxa $n=207$; Lannea microcarpa $n=61$, Mangifera indica $n=52$ and Parkia biglobosa $n=29)$ represented $70 \%$ of the sample. The tree sample $(n=497)$ had a mean CA of $38 \mathrm{~m}^{2}$ $\left(\min =1 \mathrm{~m}^{2} ; \max =606 \mathrm{~m}^{2}\right.$, s.d. $\left.=56.9\right)$, a mean height of $6.9 \mathrm{~m}(\min : 1.5 \mathrm{~m}$; max: $25 \mathrm{~m}$, s.d. $=3.5)$ and mean DBH of $28 \mathrm{~cm}(\min =3.5 \mathrm{~cm} ; \max =143 \mathrm{~cm} ; \mathrm{s.d} .=22.4)$. Vitellaria paradoxa and Lannea microcarpa cover the whole size range in the sample and are characterized by compact crowns [59]. Mangifera indica and Parkia biglobosa trees are generally large (e.g., > mean CA), where the former support a compact crown and the latter are characterized by expansive branching. Many of the species in the parkland system is pruned for fire fuel and browse [6] which introduces further complexity in the shape of the tree crowns. Eighteen of the $50 \mathrm{~m} \times 50 \mathrm{~m}$ field plots, chosen to capture the environmental complexity of the landscape, were used as reference data to guide the delineation of the tree crowns. The remaining 47 plots were used as an independent validation dataset (see Section 3.1.5).

\section{Methods}

\subsection{Automated Delineation of Tree Crowns}

The GEOBIA approach for tree crown delineation was implemented in eCognition ${ }^{\circledR}$ Developer 8.8 (Trimble) software. The algorithms applied for segmentation and the object features used for classification are briefly described in the following section, and further described in the application reference book [65]. Suitable features for object based classification were identified using the exploratory tools of eCognition. The GEOBIA approach consists of six main steps that are applied and iterated according to the flowchart shown in Figure 3. Inspiration to this approach was derived from the work of Bunting and Lucas [44]. 
Figure 3. Flowchart of the GEOBIA processing steps and their sections in the paper. Block A (inside the dotted line) is repeated to split crown clusters (Section 3.1.4).

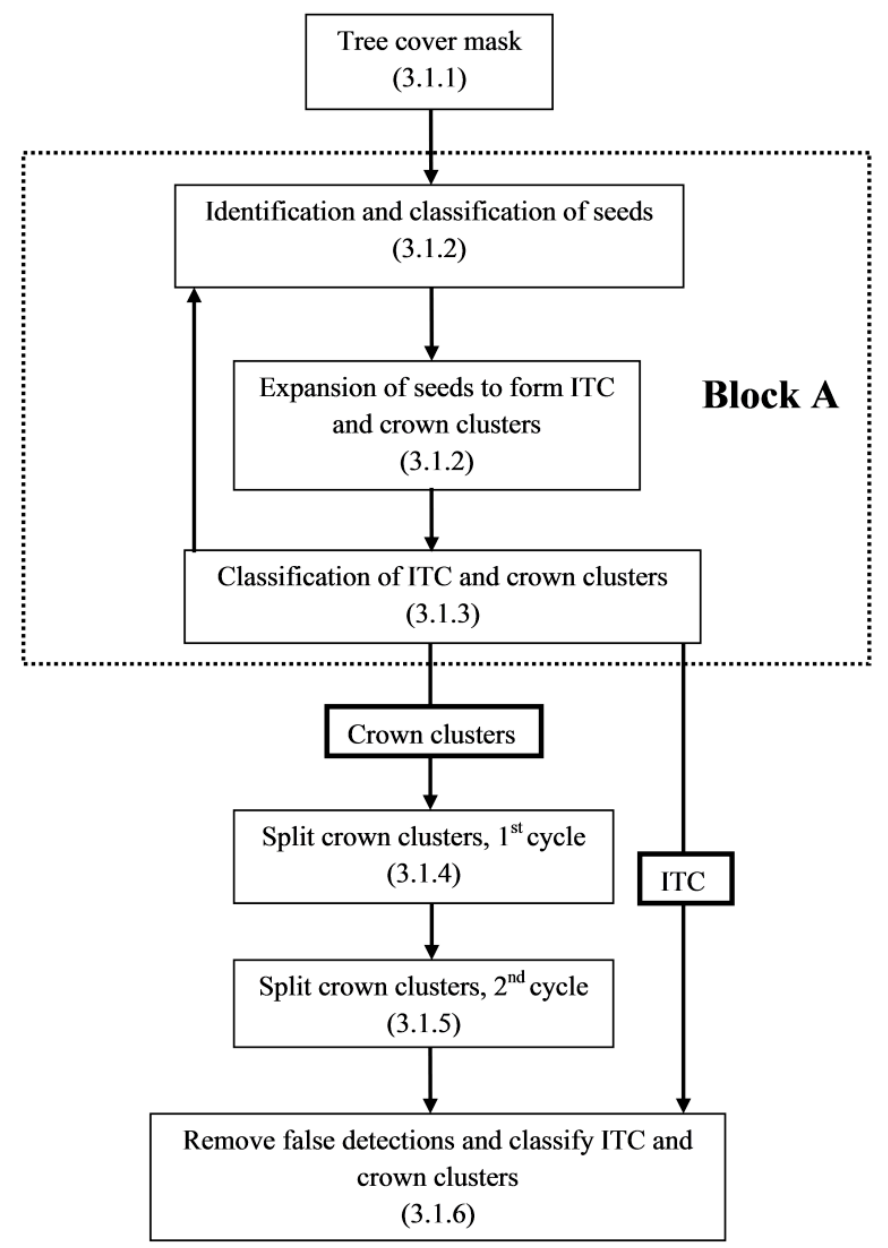

\subsubsection{Tree Cover Mask}

The first step aims to mask out non-tree cover, including water, bare soil, man-made constructions, crops and understory vegetation (i.e., grass and shrubs). A range of spectral vegetation indices, such as the NDVI, the Enhanced Vegetation Index [66] and the Forest Discrimination Index [44] were assessed for their suitability to distinguish between tree cover and non-tree cover pixels using the 18 training areas as reference data. However, none were found to provide acceptable results; conservative thresholds resulted in large areas of understory vegetation being included in the tree cover mask, whereas restrictive thresholds excluded a high proportion of trees, in particular species characterized by a low LAI. We therefore propose to base the tree cover extraction on spatial and spectral information derived from image objects that capture tree cover characteristics better than vegetation indices applied on the pixel level. Image objects were first generated by applying a threshold to the NDVI and subsequently classified according to the criteria of Table 4. This procedure is iterative; it starts at a low NDVI threshold (minthresh; 0.05) with stepwise increments (0.05) until a threshold ( max $_{\text {thresh: }}$ 0.2) is reached. Minthresh and maxthresh are determined by referring to the training areas. After each NDVI increment the pixels with values $<$ minthresh are assigned to background whereas the remaining spatially connected pixels are merged to form potential tree mask objects. Only objects 
having an area $<1500 \mathrm{~m}^{2}$ are considered for classification in order to prevent inclusion of large areas with a high proportion of background classes. The roundness and elliptical fit features were used to identify objects approximating a circular shape likely to represent a single crown or a small group of crowns. The roundness of an object is calculated as the difference between the enclosing and the enclosed ellipse, where a value of 0 represents a perfect ellipse and values $>0$ indicate a more irregular shape [65]. The elliptic fit feature superimposes an equaled area ellipse on the objects and the area of the object outside of the ellipse is compared to the area inside the ellipse, with values ranging between 0 and 1 (i.e., perfect ellipse). Since tree crown reflectance is influenced by both photosynthetic and non-photosynthetic material (i.e., leaves and branches), these objects often have higher spectral variation than for other vegetation types, in particular grass [49]. Thus, we used the object level standard deviation (s.d.) of NIR reflectance as an indicator of spectral variation to distinguish tree cover objects.

Table 4. Object features used for tree mask generation and tree crown identification.

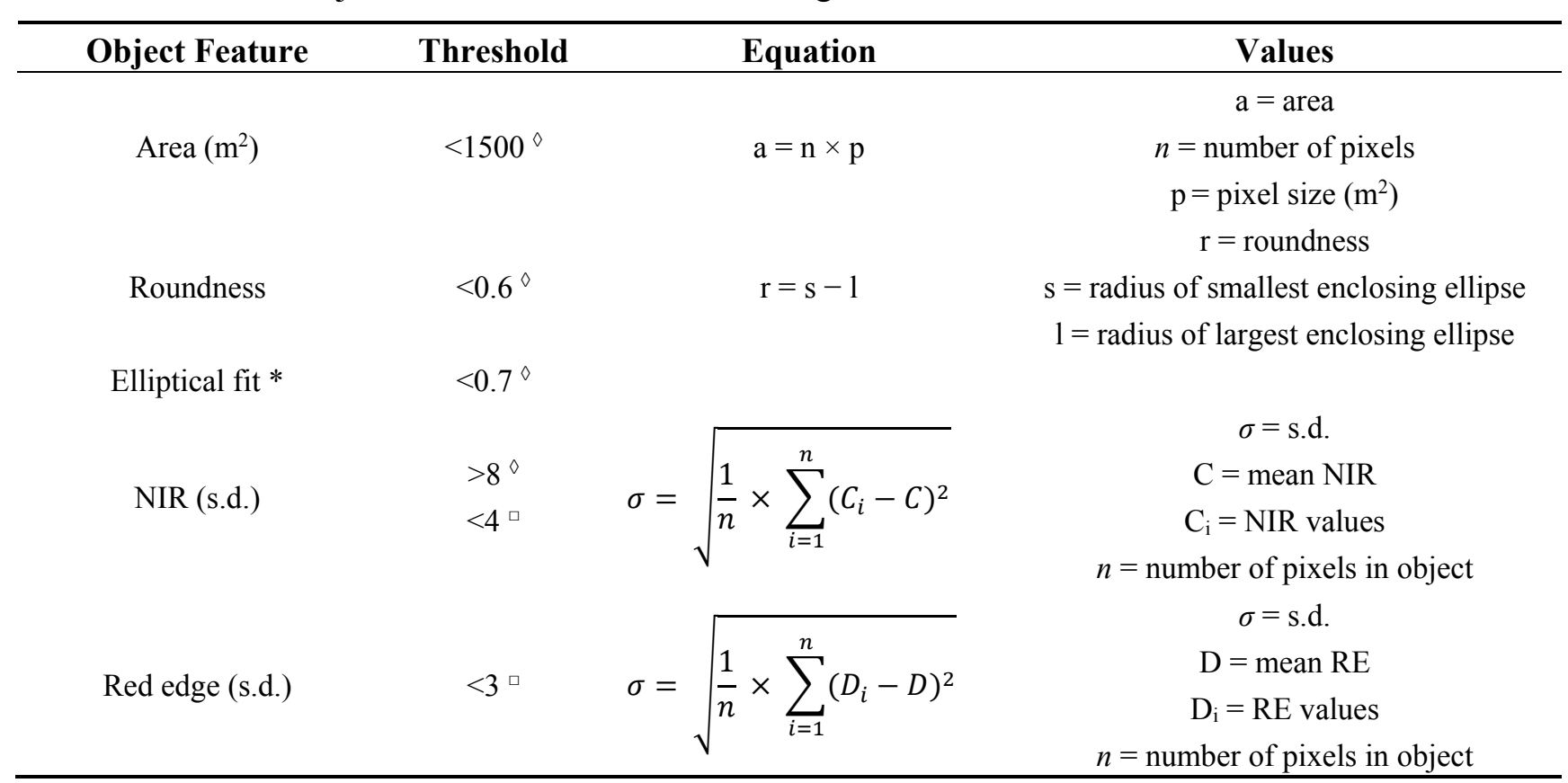

$*$ Equation can be found in $[65] ;{ }^{\diamond}$ Used for iterative NDVI threshold in tree cover mask generation; ${ }^{\square}$ Used for multi-resolution segmentation in tree cover mask generation and for individual tree crown identification (Section 3.1.6).

At this stage a significant amount of field layer vegetation was included in the tree mask and further refinement was therefore needed. First, multi-resolution segmentation [50] was performed on relatively large objects within the tree mask, with the size constraint (set to $>700 \mathrm{~m}^{2}$ ) and the scale parameter (set to 20) set sufficiently high to prevent over-segmentation of ITC. The object size threshold was set with reference to the largest trees in the training dataset, whereas the scale parameter was determined through a trial and error approach. The scale parameter (unit less) controls the degree of spectral variation within objects and therefore their resultant size. Over-segmentation of crowns results in spectrally homogeneous objects and thus dilutes the features (spectral variation) upon which the tree cover classification is based. The resulting objects were assessed for their spectral properties where a low NIR s.d. characterized background objects with a homogeneous canopy (i.e., low spectral 
variability) such as patches of grass and crops. A final refinement of the tree cover mask was then performed to remove remaining field layer vegetation, in particular shrubs and tree regrowth. This was achieved by performing an ISODATA [67] unsupervised classification on the WorldView-2 image using all eight bands within the tree cover mask, with the number of potential clusters set sufficiently high (set to 50) to limit class mixing. Clusters representing understory vegetation were identified manually and these pixels were subsequently removed from the tree cover mask.

\subsubsection{Object Maxima Identification, Classification and Expansion}

Following tree cover extraction, all adjoining tree mask objects (Figure 4) were merged. At this point small background objects $\left(<50 \mathrm{~m}^{2}\right)$ enclosed by tree mask objects were reintegrated. Such small background objects generally represented hollow, shadowed and directly sun-lit sections within large tree crowns. Within each of the individual tree mask objects a radiometric maximum (assumed to represent the tree top) was identified. Radiometric maxima were identified using NDVI and served as the starting points (i.e., seeds) for region-growing segmentation [41,44]. We located seeds using $2 \mathrm{~m}$ pixels (i.e., WorldView-2 multispectral) instead of the $0.5 \mathrm{~m}$ pan-sharpened pixels for two reasons. Firstly, seeds based on 2 m pixels were more consistently located towards the geometric centre of tree crowns compared to the $0.5 \mathrm{~m}$ pixel where within-crown variation made seed location more inconsistent (e.g., located on crown edges). Secondly, $2 \mathrm{~m}$ pixels provided a more representative characterization of the crown on which the seed was located. The mean NDVI of the seeds was used to classify the seeds into three tree species type categories (Table 5). This process guided the parameterization of the region-growing algorithm to account for tree species-type dependent variations in crown characteristics (e.g., LAI and leaf reflectance properties). A low NDVI threshold $(<0.1)$, determined from the training dataset, was set in order to minimize incorrect seed identification occurring from sparse field layer vegetation or bare ground.

Figure 4. (a) True color WorldView-2 image of active fields (bright background) and fallows (dark background); (b) tree cover mask and non-tree cover areas (blue).

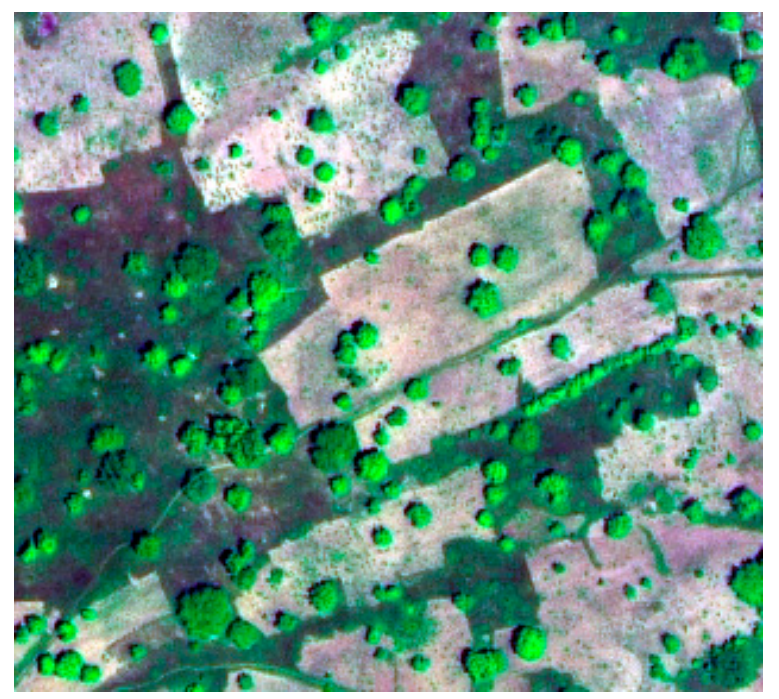

(a)

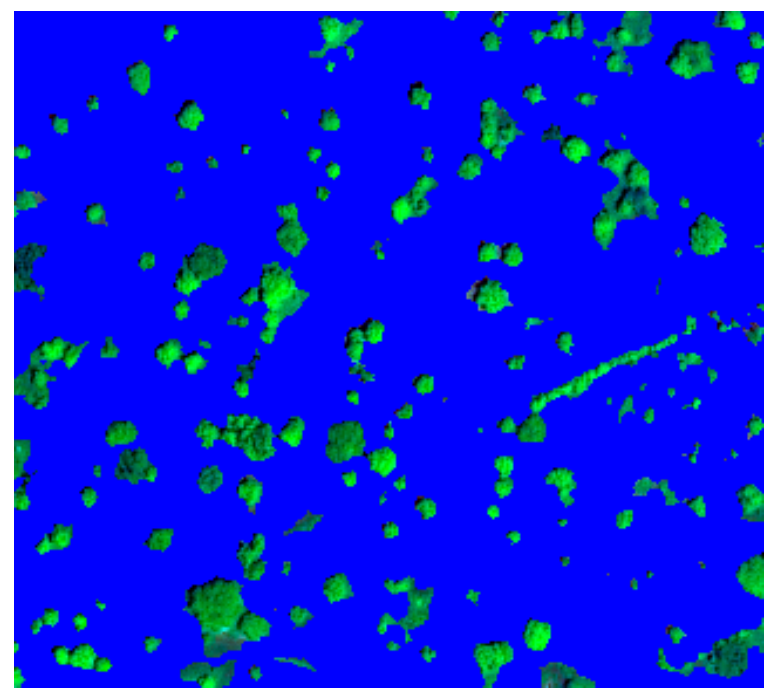

(b) 
Table 5. Classification of seeds to tree species type and region-growing thresholds established from the training dataset.

\begin{tabular}{cccc}
\hline Tree Species Type & Mean NDVI & NDVI Threshold & NIR Threshold \\
\hline Species 1 & $0.1-0.2$ & 0.08 & 30 \\
Species 2 & $>0.2-0.3$ & 0.15 & 40 \\
Species 3 & $>0.3$ & 0.18 & 50 \\
\hline
\end{tabular}

A region-growing process was then initiated where each seed expanded into adjacent $0.5 \mathrm{~m}$ pixels. The growing process was constrained by two spectral thresholds (Table 5) based on the difference in NDVI and NIR between the original seed and the adjacent candidate pixels: a sharp decrease in the NDVI and NIR values indicated crown edges. The NDVI is relatively insensitive to within-crown brightness variations and therefore suitable for detecting true crown edges while minimizing over-segmentation [49]. On the other hand, previous research suggests that NIR reflectance is particularly suitable to locate the limit between crown edges and shadows [41], thereby making it a good complement to the NDVI threshold. The spectral thresholds were optimized for tree species types as determined from the training areas. For example, trees with low LAI (i.e., low seed NDVI) contrasted less with the background; hence a lower threshold was required to prevent the region-growing algorithm to include non-tree pixels. After termination of the initial growing process a new seed was located and expanded according to the procedure described above. This process was iterated until each tree mask object was contained by potential single tree crown (i.e., "ITC") or multiple crown objects (i.e., crown cluster).

\subsubsection{Classification of Crowns and Crown Clusters}

The objects generated by the region-growing segmentation can either represent an ITC, or a crown cluster that needs to be further segmented. The stage presented in this section separates ITC from crown clusters by use of geometric object features. ITC and crown clusters were classified based on features that characterize object shape, with thresholds determined from the training data. We used the ratio of length to width to identify asymmetric or elongated objects (threshold $>1.7$ ), which were likely to represent crown clusters. The roundness feature was used to identify highly irregularly-shaped objects (threshold $>0.6$ ). Object area was used to limit the possible extent of the delineated tree crowns (threshold $>700 \mathrm{~m}^{2}$ ). Objects considered to represent ITC were temporarily removed from the data (see Figure 3), allowing those objects identified as crown clusters to be further segmented into ITC (procedures outlined in following sections).

\subsubsection{Splitting Crown Clusters, 1st Cycle}

In order to extract ITC from objects classified as crown clusters, the steps (Section 3.1.2; Section 3.1.3) of Block A (Figure 3) were iterated in two cycles where the spectral thresholds (Table 5) used for the region-growing algorithm were decreased stepwise (via multiplication with a factor of 0.75). By decreasing the spectral thresholds, more subtle crown edges could be detected, facilitating crown delineation in areas where contrast with the adjacent field layer was low. Two cycles of crown 
cluster splitting were used, based on a compromise between processing time and enabling crown delineation for varying field layer conditions.

\subsubsection{Splitting Crown Clusters, 2nd Cycle}

The objects still classified as crown clusters after the two cycles (3.1.4) were considered problematic to split based on spectral thresholds. Thus, we applied morphological watershed segmentation that splits objects based on shape characteristics instead of spectral gradients [68]. More specifically, for each pixel contained within the individual crown cluster object, the inverted distance to the closest object border is calculated. The resulting local minima serve as seeds in a region-growing that terminates when the borders of the new objects meet. The watershed segmentation is most suited to delineate ITC of elongated and sprawling crown clusters which conform to the assumptions of the algorithm [49]. It may, however, cause over-segmentation of compact crown clusters resulting in inaccurate crown delineation.

\subsubsection{Removal of False Detections and Classification of Crowns and Crown Clusters}

In the final step of the process, the delineated objects undergo two classification procedures which separate false detections, ITC and crown clusters. Firstly, false detections are identified and removed using NIR and RE s.d. thresholds (Table 4). Secondly, the objects derived from the crown cluster splitting procedures (3.1.4 and 3.1.5) are evaluated according to the geometric features of Table 4 . Adjacent objects classified as crown clusters are subsequently merged to correct for over-segmentation of compact objects. We considered the splitting of such crown clusters to be beyond the capabilities of the WorldView-2 data and the proposed GEOBIA approach.

\subsubsection{Accuracy Assessment}

In order to assess the reliability of the method we compared the delineated tree crowns with an independent reference dataset representing individual tree positions with associated attributes (e.g., species, DBH and CA). Initial trials revealed that automated matching of field trees and delineated crown objects was difficult due to the complex and multilayered tree cover structure. Thus, an accuracy assessment was performed where field trees and delineated crown objects were associated manually. The assessment focuses on two aspects of accuracy: tree detection accuracy and crown delineation accuracy.

To assess tree detection accuracy (Table 6), we recorded the number of field trees that were clearly associated with a single crown object presenting a one to one relationship (individual tree detection; ITD), the errors of omission (EO) and the errors of commission (EC). The overall detection accuracy was based on Poulion et al.'s (2002) accuracy index [69], defined as:

$$
\text { Accuracy Index }(\%)=(n-(O+C)) / n \times 100
$$

where $\mathrm{O}$ and $\mathrm{C}$ represent the numbers of omission and commission errors, respectively, and $\mathrm{n}$ represents the total number of field trees in the accuracy assessment dataset. We also recorded the cases where multiple field trees were contained by a single crown object, including the number of trees in the crown cluster (crown cluster detection; CCD). 
Table 6. Definitions of measures used for detection accuracy assessment.

\begin{tabular}{ccc}
\hline Measure & Description & Unit \\
\hline ITD & Individual tree detection & $\%$ \\
CCD & Crown cluster detection & $\%$ \\
OE & Omission error & $\%$ \\
CE & Commission error & $\%$ \\
\hline
\end{tabular}

For assessing the crown delineation accuracy, the CA of field trees was compared to the CA of the delineated crown objects, for both ITC and crown clusters. The CA of the individual field trees associated with crown clusters (CCD) was aggregated to enable quantitative comparison to the delineated objects. In order to assess the delineation, three measures of accuracy were used: (1) the correlation coefficient (Spearman's Rho; $r_{s}$ ) between field CA and delineated CA; (2) the mean absolute error (MAE) between field CA and delineated CA [70]; (3) the mean relative error (MRE), defined here as the averaged ratio of the absolute error to field CA; and, (4) the mean bias error (MBE), defined here as the difference between the mean delineated CA and the mean field CA, which indicates the degree of over- or under-estimation. The statistical analyses were performed using the Statistical Package for the Social Sciences (SPSS) 21 software.

We assessed the delineation accuracy for ITC, crown clusters and tree canopy cover. For the ITC, three crown size classes were assessed separately: small trees (CA $<35 \mathrm{~m}^{2}$ ), medium trees (CA 35-100 $\mathrm{m}^{2}$ ) and large trees $\left(\geq 100 \mathrm{~m}^{2}\right.$ ). Separate assessments stratified by land use (i.e., active field and fallow) were also performed. To assess the accuracy of tree canopy cover estimation, plot level aggregates of field tree CA were compared to the CA of all delineated crown objects, including the errors of commission.

\section{Results and Discussion}

\subsection{Detection Accuracy}

When detection accuracy is defined as a 1:1 correspondence between field trees and delineated objects (ITD), the results of this study are modest: $48.4 \%$ of the trees $>5 \mathrm{~cm}$ and $53.8 \%$ of trees $>10 \mathrm{~cm}$ DBH were detected as ITC (Table 7). Detection accuracy of ITC appears to be affected by the vegetation conditions in the fallow plots, as reflected by the lower detection rates. This finding is in line with research conducted in other woodland areas, which suggests that detection rates normally decline with increasing tree density $[41,44]$. When the definition of accuracy is relaxed to also include crown clusters as correct detections, the results improved to $85.7 \%$ of the trees $>5 \mathrm{~cm}$ DBH being correctly detected. Allowing crown clusters as a mapping unit is a reasonable approach in this situation considering the patchiness of the tree cover structure [41,44] and the resolving power of the WorldView-2 imagery. 
Table 7. Results of detection accuracy assessment showing detection rate (DR; \%), omission error $(\mathrm{OE} ; \%)$, commission error $(\mathrm{CE} ; \%)$ and accuracy index (AI; \%).

\begin{tabular}{|c|c|c|c|c|c|c|}
\hline $\begin{array}{c}\text { Land } \\
\text { Use } \\
\end{array}$ & $\begin{array}{l}\text { Field } \\
\text { Trees }\end{array}$ & $\begin{array}{c}\text { DR } \\
(\text { ITC) }\end{array}$ & $\begin{array}{c}\text { DR (ITC and } \\
\text { Crown Clusters) }\end{array}$ & OE & $\mathbf{C E}$ & AI \\
\hline $\begin{array}{l}\text { Active } \\
\text { field }\end{array}$ & 189 & $55^{1 / 60.7} 7^{2}$ & $88.4^{1}$ & $11.6^{1 / 5.3^{2}}$ & 12.7 & $76^{1 / 79^{2}}$ \\
\hline Fallow & 308 & $43.8^{1 / 48.4^{2}}$ & $87.7^{1}$ & $12.3^{1 / 9.3^{2}}$ & 21.7 & $66^{1 / 64.5^{2}}$ \\
\hline Total & 497 & $48.4^{1 / 53.8^{2}}$ & $85.7^{1}$ & $14.3^{1 / 6.6^{2}}$ & 18.3 & $67.4^{1} / 69.7^{2}$ \\
\hline
\end{tabular}

Figure 5. Diagrams presenting statistics for (a) omission errors and (b) commission errors. The bar-charts show the errors distributed in size classes, whereas the pie-charts show the distribution of errors in the two land-use categories (active field and fallow).
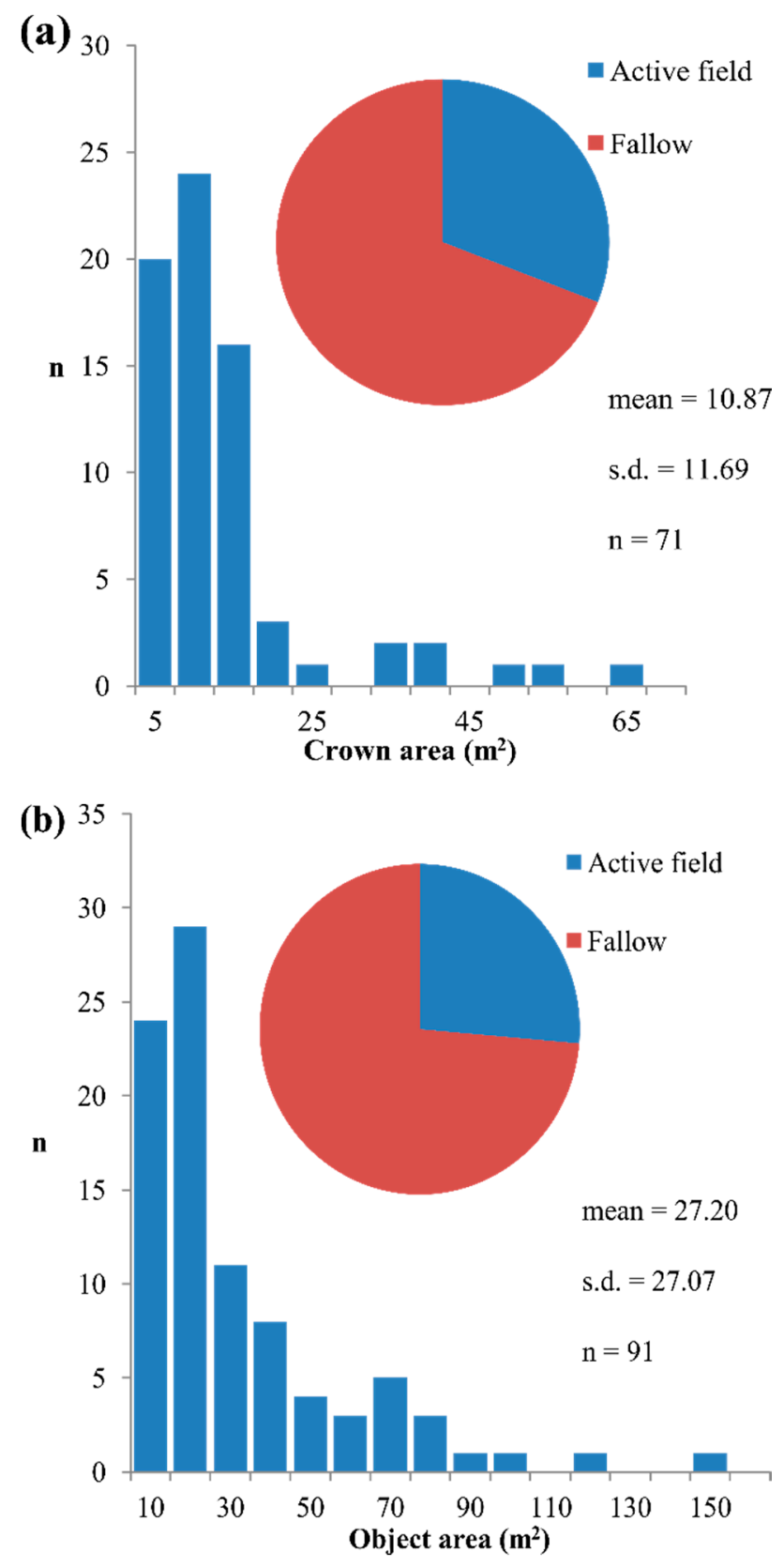
Our results compare well to similar studies that have applied GEOBIA for tree crown mapping and have considered crown clusters as correct detection. For example, Ardila et al. reported a detection rate between $70 \%-80 \%$ using Quickbird imagery to map urban tree cover in the Netherlands [48], and Bunting and Lucas reported a detection rate of $71 \%$ using Compact Airborne Spectrographic Imager (CASI) imagery in Australian woodlands [44]. Also using CASI imagery, but applying the valley-following approach [42], Leckie et al. achieved a detection rate between $50 \%-60 \%$ for an old growth conifer area in Canada [20]. Higher accuracies have been reported in less complex tree cover conditions, for example by Pouliot et al., who achieved a detection rate of $91 \%$ for a spruce plantation using a modified local maxima approach and multispectral aerial imagery [69].

The total proportion of omission errors (total $=14.3 \%)$ is acceptable in both active field $(11.6 \%)$ and fallow plots $\left(12.3 \%\right.$ ), with omissions attributed mainly to missing small trees with $\mathrm{CA}<15 \mathrm{~m}^{2}$ (Figure 5a), which corresponds to an area less than four multispectral WorldView-2 pixels ( $2 \mathrm{~m})$. No consistent relationship was found between tree species and the errors of omission which suggests that the WorldView-2 imagery was acquired during a stable phenological stage (early dry season) when the deciduous woodland tree species have favorable canopy conditions for remote sensing analysis. These results also suggest that the method used to create the tree cover mask (Section 3.1.1) enables an acceptable separation between tree cover and field layer objects (e.g., grass, shrub and tree re-growth) that are spectrally similar on the pixel level and therefore problematic to separate using vegetation indices or pixel based classification. In particular the geometric information facilitated the inclusion of small trees and tree species with low LAI (i.e., partly senescent crowns whose reflectance is highly influenced by the field layer), which are easily misclassified with purely spectral approaches.

The total proportion of commission error is $18.3 \%$ (Figure $5 \mathrm{~b}$ ), and occurs most for objects with an area below the reference sample mean (i.e., $<38 \mathrm{~m}^{2}$ ). The error rate is considerably lower in active fields $(12.3 \%)$ as compared to fallows $(21.7 \%)$ where small tree re-growth $(<5 \mathrm{~cm} \mathrm{DBH})$ is more abundant. The relatively high error rate is expected due to the similarities in the spectral response between tree crowns and tree re-growth, especially when the latter is arranged in crown clusters that exceed the extent of the $2 \mathrm{~m}$ multispectral WorldView-2 pixels (i.e., $>4 \mathrm{~m}^{2}$ ). Since the field reference dataset was restricted to trees with $\mathrm{DBH}>5 \mathrm{~cm}$ to ensure a reasonable workload, the interpretation of the commission error rate is not straight forward and could to some extent conceal detections of small trees. However, high commission error is a well-known limitation and therefore a central issue for research on tree crown detection in HSR imagery [34]. Unfortunately, quantifications of commission errors are not reported as frequently in the literature as detection accuracy (including error of omission), which reduces the possibilities for inter-study comparisons. The commission error rate in the present study $(18.3 \%)$ is lower than that reported for comparable tree cover conditions, for example 26\% for urban tree cover in the Netherlands [48] and 25\% in Canadian old growth forest [20]. Lower rates of commission errors $(3.0 \%-14.6 \%)$ have been reported for spruce and pine plantations in Canada, particularly in cases where leaf-off imagery has been used in the analysis $[38,69]$. The commission errors in the present study could possibly be further reduced by applying more advanced methods for feature optimization in the creation of the tree cover mask, for example using classification trees [71]. Alternatively, a canopy height model derived from airborne LiDAR or alternatively HSR satellite stereo imagery [72] could be used to mask out small trees below a certain height and thus minimize commission errors resulting from tree re-growth. 


\subsection{Delineation Accuracy}

Results from the delineation accuracy assessment are presented (Table 8 and Figure 6) for different levels of tree crown aggregation (ITC and crown clusters), tree crown size classes (small, medium and large) and land-use categories (active field and fallow). The correlation coefficients $\left(r_{s}\right)$ presented in Table 8 and Figure 6 are all highly significant $(<0.05)$ and show that the delineation accuracy is a function of tree crown size with lowest $r_{s}$ for small trees (0.419) and highest $r_{s}$ for large trees (0.905). The MRE shows a similar pattern: the delineation of small tree crowns results in the highest relative error $(65 \%)$ and the delineation of large tree crowns results in the lowest relative error $(21.3 \%)$. Furthermore, assessment of the individual errors revealed that the delineation tended to overestimate the $\mathrm{CA}$ of small trees $(\mathrm{MBE}=4.0)$, whereas it underestimated the CA of medium and large trees $(\mathrm{MBE}=-41.8)$. Overestimation of $\mathrm{CA}$ for small trees was primarily caused by the presence of adjacent field layer vegetation that diluted the crown edges in the NDVI image used for region-growing segmentation. Furthermore, small trees cause less distinct shadows which reduced the effectiveness of using NIR reflectance for crowns edge detection in HSR imagery. The underestimation of large trees was primarily the result of high spectral variance near crown edges where the foliage was more open and where field layer reflectance had a strong influence on the spectral response. Such within-crown spectral variance was in some cases confused for crown edges by the region-growing segmentation. This effect was especially apparent for tree species characterized by expansive branching (e.g., Parkia bigloba and Adansonia digitata). Thus, our results from using NDVI and NIR, in combination with thresholds optimized for tree species types (Section 3.1.2) in the region-growing segmentation indicates two things. Firstly, the approach was moderately successful in delineating small tree crowns, in particular those which display low contrast to the field layer. Secondly, the higher delineation accuracies for medium and large trees suggest that the approach reduces the effect of within-crown spectral variance, but does not remove it completely.

Table 8. Results of accuracy assessment for the delineation of ITC and crown clusters presented by Spearman's Rho correlation coefficient $\left(r_{s}\right)$, mean absolute error (MAE), mean relative error (MRE), and mean bias error (MBE).

\begin{tabular}{|c|c|c|c|c|c|c|}
\hline $\begin{array}{c}\text { Level of } \\
\text { Aggregation }\end{array}$ & Category & $r_{s}$ & $\begin{array}{c}\text { MAE } \\
\left(\mathbf{m}^{2}\right)\end{array}$ & $\begin{array}{c}\text { MRE } \\
(\%)\end{array}$ & $\begin{array}{l}\text { MBE } \\
\left(\mathbf{m}^{2}\right)\end{array}$ & $\mathbf{n}$ \\
\hline \multirow{6}{*}{ ITC } & Small CA $\left(<35 \mathrm{~m}^{2}\right)$ & 0.419 & 8.5 & 65.0 & 4.0 & 122 \\
\hline & Medium CA $\left(35-100 \mathrm{~m}^{2}\right)$ & 0.613 & 15.2 & 26.8 & -6.9 & 85 \\
\hline & Large CA $\left(\geq 100 \mathrm{~m}^{2}\right)$ & 0.905 & 44.5 & 21.3 & -41.8 & 31 \\
\hline & All (active field) & 0.877 & 16.5 & 30.0 & -12.5 & 107 \\
\hline & All (fallow) & 0.804 & 14.8 & 58.0 & -0.5 & 131 \\
\hline & All (fallow + active field) & 0.836 & 15.6 & 45.6 & -5.8 & 238 \\
\hline \multirow{3}{*}{ Crown clusters } & Active field & 0.860 & 27.2 & 32.7 & -7.1 & 21 \\
\hline & Fallow & 0.739 & 35.0 & 77.0 & 24.3 & 39 \\
\hline & All & 0.800 & 32.3 & 61.5 & 13.3 & 60 \\
\hline \multirow{3}{*}{ ITC and crown clusters } & Active field & 0.892 & 18.2 & 30.7 & -11.7 & 128 \\
\hline & Fallow & 0.808 & 19.5 & 62.5 & 5.2 & 170 \\
\hline & All & 0.836 & 18.9 & 48.8 & -2.0 & 298 \\
\hline
\end{tabular}


Figure 6. Graphs of the correlation between field data and remote sensing data (delineated) showing (a) crown area of ITC; (b) crown cluster area; and (c) tree canopy cover.
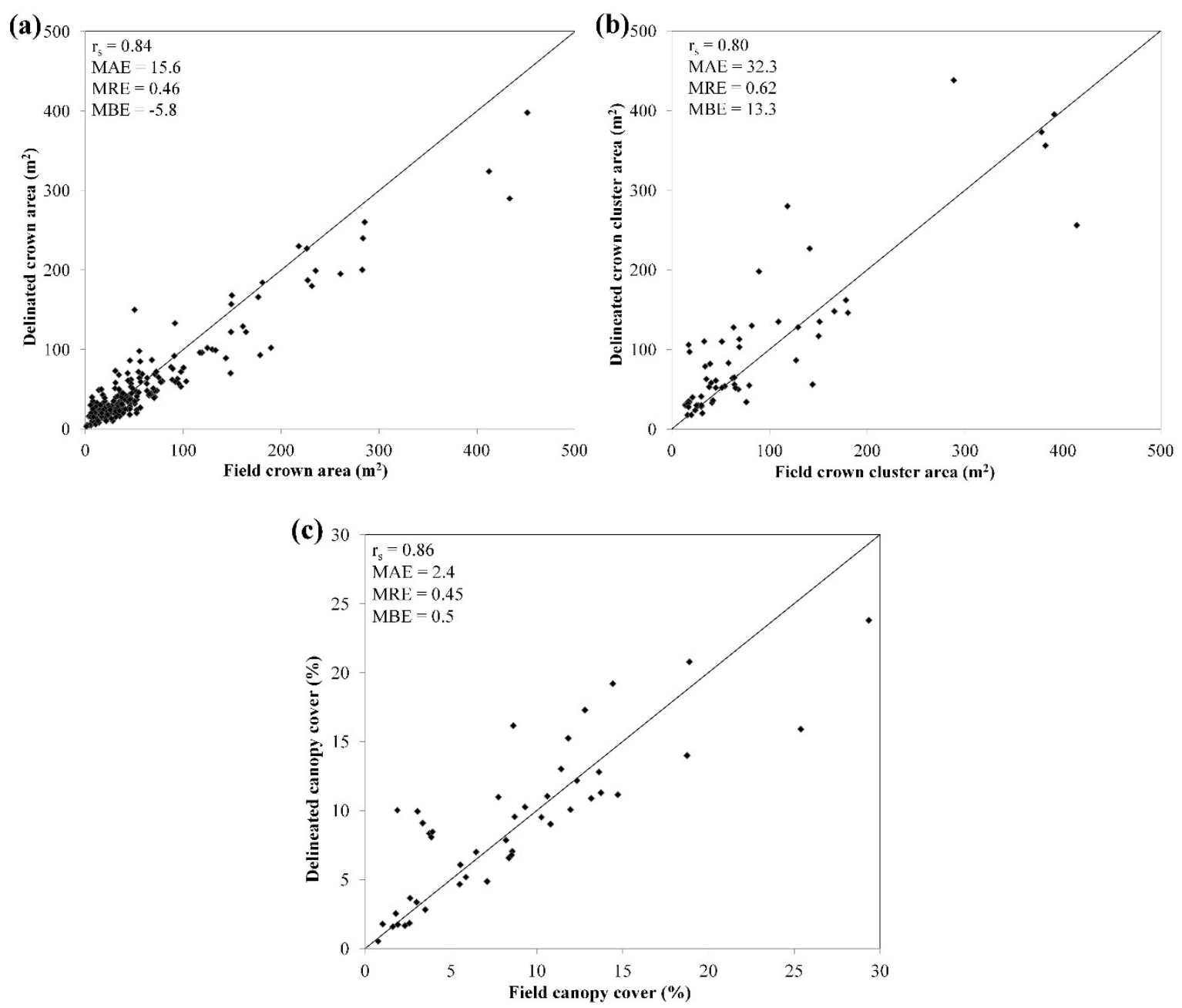

The overall delineation accuracy of ITC in this study $\left(r_{s}=0.836\right.$, MAE $=15.6 \mathrm{~m}^{2}$, $\mathrm{MRE}=45.6 \%$ ) is in line with previous research. For example, Ardila et al., reported a relative error of $40 \%$ compared to a manually delineated reference dataset [48]. Brandtberg and Walter reported a relative error of $46 \%$ when delineated ITC were compared to a field reference dataset [73]. Delineation errors as low as $17.9 \%$ have been achieved in even aged and well-spaced plantation forests [69]. However, lower delineation accuracies are to be expected in situations where the tree cover is characterized by high heterogeneity in terms of tree crown size distribution [20] and tree species diversity [34]. Consequently, the delineation accuracy achieved here must been contrasted to the wide tree crown size range $\left(\mathrm{CA}=1-600 \mathrm{~m}^{2}\right)$ and the relatively high tree species diversity observed in the study area.

The delineation accuracy for crown clusters is lower than for ITC, expressed in $r_{s}(0.800)$, MAE $\left(32.3 \mathrm{~m}^{2}\right)$ and MRE (61.5\%). To derive "field crown cluster area", the CA of individual trees measured in the field and included in the delineated crown cluster was aggregated without taking into account potential crown overlaps (Section 2.3). Since large trees in the clusters are likely to overtop, and thus obscure others from the view of the satellite sensor, this approach tends to overestimate field crown cluster area. An accurate delineation is therefore expected to underestimate crown cluster area to some 
degree. This effect is discernible in the active field plots (Table 8), but not in the fallow plots where overestimation of crown cluster area occurred due to the erroneous inclusion of adjacent field layer vegetation.

The tree canopy cover derived from the delineation agrees well with the reference data (Table 9; Figure 6c) in terms of $r_{s}(0.859)$ MAE $(2.4 \%)$ and MRE (45\%). The agreement is considerably better for plots in active fields $\left(r_{s}=0.965\right)$ compared to fallow $\left(r_{s}=0.707\right)$. Since the reference tree canopy cover was calculated by aggregating the $\mathrm{CA}$ of all trees on the plot level, some overestimation is induced because large trees may overtop or overlap (smaller) adjacent trees. This means that the delineation is expected to underestimate tree canopy cover slightly, which is the case for the plots in active fields $(\mathrm{MBE}=-1)$. However, since every delineated object (including commission errors) is used to calculate tree canopy cover, the underestimation is expected to be reduced. This is especially apparent in the fallow plots where the delineation overestimates tree canopy cover as a result of the higher frequency of commission errors (Figure 5b). Our results compare well with similar studies in terms of accuracy. For example, Rasmussen et al., reported an agreement of $r^{2}=0.51$ between observed (field) and delineated tree canopy cover for an open woodland area in northern Senegal [21], whereas Morales et al., reported $r^{2}=0.86$ and MAE $=1.9 \%$ in a Hawaiian dry forest [74].

Table 9. Results of accuracy assessment for the delineation of tree canopy cover presented by Spearman's Rho correlation coefficient $\left(r_{s}\right)$, mean absolute error (MAE), mean relative error (MRE), and mean bias error (MBE). Ease.

\begin{tabular}{cccccc}
\hline Category & $\boldsymbol{r}_{\boldsymbol{s}}$ & MAE (\%) & MRE (\%) & MBE (\%) & n \\
\hline Active field & 0.965 & 2.1 & 24 & -1 & 22 \\
Fallow & 0.707 & 2.7 & 64 & 1.8 & 24 \\
All & 0.859 & 2.4 & 45 & 0.5 & 46 \\
\hline
\end{tabular}

In general, the delineation accuracies for ITC, crown clusters and tree canopy cover were consistently lower in the fallows compared to the active fields. Two main factors cause this difference. Firstly, the higher abundance of field layer vegetation in the fallows complicated the crown edge detection in region-growing segmentation. Secondly, the trees in fallows were generally smaller (mean $\mathrm{CA}=51.4 \mathrm{~m}^{2}$ ) than trees in active fields (mean $\mathrm{CA}=66.0 \mathrm{~m}^{2}$ ) and therefore more difficult to delineate (Table 8). This difference in tree size distribution is likely the results of local land management where a high proportion of the small trees are removed, while large trees are retained when the land is cleared prior to cultivation [6].

\subsection{Considerations for Wider Application}

The tree crown mapping approach presented in this article was designed to account for variability in tree crown size, canopy spectral properties (e.g., different tree species) and field layer conditions. The design included use of geometric and spectral thresholds for the separation of tree cover from field layer components (3.1.1. and 3.1.6.), the definition of crown edges (3.1.2. and 3.1.4.) and the classification of ITC and crowns clusters (3.1.3 and 3.1.6.). These thresholds were determined from a limited, yet structurally complex, $10 \mathrm{~km} \times 10 \mathrm{~km}$ study area. It is reasonable to believe that the geometric thresholds will remain consistent for other woodland areas with similar vegetation 
characteristics, even in cases when imagery from different HSR remote sensing systems or vegetation seasons is used. However, attention should be given to the sun-sensor geometry at the time of image acquisition since this may significantly affect the visibility and appearance of trees in HSR imagery [41], especially for tree cover with mixed tree sizes and heights [20]. The spectral thresholds, on the other hand, are to some extent sensor (WorldView-2) specific, in particular those that are based on red edge reflectance. The specific values of the single band thresholds (e.g., NIR and red edge) applied in this study would need to be adjusted to account for differences in vegetation and atmospheric conditions. Identification of optimal spectral threshold values should be based on empirical evaluation, a process that is significantly aided by a priori knowledge about the structure and spectral properties of the local tree species and field layer components. Given the massive amount of potential object features available in GEOBIA [51], improvements in detection and delineation accuracies may be achieved by application of advanced optimization procedures for feature selection and threshold determination e.g., [71].

Similar to related research, we found that detection and delineation accuracies are higher in areas were the tree density is low and the understory vegetation is largely senescent. This suggests that the proposed combination of GEOBIA and HSR imagery is most useful for tree crown mapping in sparse woodlands, such as the West African parklands, whereas further research will be required to ensure accurate application in denser woodlands. Our results further suggest that in cases where trees crowns are strongly interlocked and arranged in compact crown clusters, individual tree crown mapping using HSR imagery may not always be a plausible expectation. Under these conditions, ITC delineation based on spectral gradients (e.g., NDVI and NIR) and object shape characteristics (i.e., watershed segmentation) may be less successful. However, previous research argues that the mapping of crown clusters provides a useful means to model and analyze structural tree cover attributes, especially in areas characterized by high spatial heterogeneity such as African woodlands [41,54,55,75].

Preliminary results based on the reference dataset show strong relationships between delineated CA and tree height $\left(r_{s}=0.711\right)$ and DBH $\left(r_{s}=0.735\right)$, which suggests that the proposed method can be used to estimate these and related structural variables (e.g., biomass) over relatively large areas. Further analysis will be required to establish relationships between cluster area and tree cover structure in parklands and other woodland areas. Moreover, accurate maps of crown clusters and associated spatial attributes (e.g., size and shape) are highly relevant for ecological research targeting woodland and savanna landscapes in which the concept of patch dynamics is central $[75,76]$. The approach presented in this article represents an efficient means to extract detailed tree cover data from easily accessible, albeit relatively expensive, satellite imagery. Such spatially explicit datasets are critical for inventory and monitoring of African woodlands and facilitate improved understanding of tree cover structure, composition and dynamics. Detailed datasets of tree cover structure also provides a practical means to scale field observation to medium and coarse spatial resolution RS data, thereby facilitating monitoring at multiple spatial scales e.g., [77].

\section{Conclusions and Future Research}

This study aimed to evaluate the effectiveness of using WorldView-2 satellite imagery and GEOBIA for automating tree crown mapping in African woodlands, in particular agroforestry parkland 
landscapes. The geographical focus is one of the main contributions of this work since limited research has targeted the potential of HSR satellite imagery for forestry applications in African woodlands. HSR satellite systems represent a feasible alternative to airborne RS systems, especially in Africa where the availability of such equipment is highly limited.

The results show that reasonably accurate tree crown maps can be extracted from HSR satellite imagery (WorldView-2) by using a combination of spectral and geometric information derived from GEOBIA. The moderate detection accuracies (48.4\%-53.8\% for ITC) agree with previous research on tree crown mapping in complex environments and reflect the difficulty of resolving individual tree crowns in HSR imagery, especially in cases where tree crowns are interlocked to form compact crown clusters. The results improved considerably ( $85.7 \%$ accuracy for ITC and crown clusters) when crown clusters were considered as correct detections, suggesting this to be a reasonable mapping approach given constraints imposed by imagery characteristics and tree cover conditions. In a later stage of the analysis, ITC and crown clusters can be differentiated using the geometric information (e.g., shape and size) inherent to GEOBIA. The results further show that ITC and crown cluster area can be estimated with reasonable accuracy from the delineated objects. For small trees $\left(<35 \mathrm{~m}^{2}\right)$, delineation accuracy is relatively low $\left(r_{s}=0.419 ; \mathrm{MRE}=65 \%\right)$ and the crown area is overestimated. For medium $\left(35-100 \mathrm{~m}^{2}\right)$ and large $\left(\geq 100 \mathrm{~m}^{2}\right)$ trees, the delineation accuracy is considerably higher $\left(r_{s}=0.836-0.905\right.$; MRE $=21.3 \%-26.8 \%$ ) and crown area is slightly underestimated. Delineation accuracy for crown clusters is lower $\left(r_{s}=0.800\right.$; MRE $\left.=61.5 \%\right)$, in part possibly reflecting the complicated task of measuring crown cluster area in the field.

Detection and delineation accuracies are consistently lower in the fallows compared to active fields for three reasons: (i) tree density is higher; (ii) trees size is smaller and (iii) the understory vegetation is denser. The dense understory vegetation in fallows is to a large extent composed of trees with $\mathrm{DBH}<5 \mathrm{~cm}$ (e.g., re-growth), which causes high commission error rates. Substantial improvements in terms of commission error, as well as delineation accuracy, may be achieved by developing the method used for extracting the tree cover mask (Section 3.1.1). For example, future research should investigate the potential of advanced feature optimization procedures which may make better use of the vast spectral, geometric, textural and relational information available in HSR imagery through the application of GEOBIA. Alternatively, use of 3D information such as that derived from airborne LiDAR or HSR satellite imagery acquired in stereo pairs provides a means to derive canopy height models. Such models may both enable a more effective exclusion of understory vegetation and improve the possibilities to detect tree crown edges through region-growing segmentation.

The results of this work were limited to the $100 \mathrm{~km}^{2}$ study area located in the parklands of Saponé, Burkina Faso. Similar results, in terms of detection and delineation accuracies, are expected when the proposed method is applied in areas with similar tree cover structure. However, adjustment of thresholds, in particular those based on spectral information, may be required in order to account for differences in atmospheric and tree canopy conditions, and imagery characteristics. For following research, the application of the GEOBIA approach in other woodland and parkland areas is necessary to assess its consistency and transferability. 


\section{Acknowledgments}

The research work and the publication has been funded by the Swedish International Development Cooperation Agency (Sida), the Swedish Energy Agency and the Swedish Research Council (VR/Sida). The study was conducted in close collaboration with the Institut de l'Environnement et de Recherches Agricoles (INERA) in Burkina Faso. Huges Bazié and Josias Sanou are thanked for arranging the practicalities of the field campaign. The fieldwork would not have been possible without the expertise and assistance of Tankoano Boalidioa. The farmers in Saponé are thanked for their permission to perform the tree inventory. Kenneth Olofsson and Tina Neset provided constructive input to the manuscript. Lastly, we thank the anonymous reviewers who helped improving the overall quality of the paper.

\section{Author Contributions}

Martin Karlson designed the study, conducted the fieldwork, performed the image processing and analysis and prepared the manuscript. Madelene Ostwald initiated the work and took part in the study design and fieldwork. Madelene Ostwald and Heather Reese contributed to the design of the analysis, discussion and edited the manuscript.

\section{Conflicts of Interest}

The authors declare no conflict of interest.

\section{References}

1. Chidumayo, E.N.; Gumbo, D.J. The Dry Forests and Woodlands of Africa: Managing for Products and Services; Earth Scan: London, UK, 2010; p. 288.

2. White, F. Vegetation of Africa: A Descriptive Memoir to Accompany the UNESCO/AETFAT/UNSO Vegetation Map of Africa; UNESCO: Paris, France, 1983; p. 356.

3. Mayaux, P.; Bartholome, E.; Fritz, S.; Belward, A. A new land-cover map of Africa for the year 2000. J. Biogeogr. 2004, 31, 861-877.

4. Chidumayo, E.; Marunda, C. Dry forests and woodlands in sub-Saharan Africa: Context and challenges. In The Dry Forests and Woodlands of Africa: Managing for Products and Services; Chidumayo, E.N., Gumbo, D.J., Eds.; Earth Scan: London, UK, 2010; pp. 1-11.

5. United Nations Environmental Programme (UNEP). Livelihood Security. Climate Change, Migration and Conflict in the Sahel; UNEP: Geneva, Switzerland, 2011.

6. Boffa, J.M. Agroforestry Parkland in Sub-Saharan Africa: FAO Conservation Guide 34; United Nations Food and Agricultural Organization: Rome, Italy, 1999.

7. Zomer, R.J.; Trabucco, A.; Coe, R.; Place F. Trees on farm: Analysis of Global Extent and Geographical Patterns of Agroforestry. Working Paper No. 89; The World Agroforestry Centre: Nairobi, Kenya, 2009.

8. Timberlake, J.; Chidumayo, E.; Sawadogo, L. Distribution and characteristics of African dry forests and woodlands. In The Dry Forests and Woodlands of Africa: Managing for Products and Services; Chidumayo, E.N., Gumbo, D.J., Eds.; Earth Scan: London, UK, 2010; pp. 11-43. 
9. Bayala, J.; Sanou, J.; Teklehaimanot, Z. Parklands for buffering climate risk and sustaining agricultural production in the Sahel of West Africa. Curr. Opin. Environ. Sustain. 2014, 6, $28-34$.

10. Gonzalez, P. Desertification and a shift of forest species in the West African Sahel. Clim. Res. 2001, 7, 217-228.

11. Gonzalez, P.; Tucker, C.J.; Sy, H. Tree density and species decline in the African Sahel attributable to climate. J. Arid Environ. 2012, 78, 55-64.

12. Maranz, S. Tree mortality in the African Sahel indicates an anthropogenic ecosystem displaced by climate change. J. Biogeogr. 2009, 36, 1181-1193.

13. Lykke, A.M. Assessment of species composition change in savanna vegetation by means of woody plants' size class distributions and local information. Biodivers. Conserv. 1998, 7, 1261-1275.

14. Saul, M.; Ouadba, J.M.; Bognounou, O. The wild vegetation cover of western Burkina Faso: Colonial policy and post-colonial development. In African Savannas: Global Narratives and Local Knowledge of Environmental Change; Basset, T.J., Crummey, D., Eds.; James Currey: Oxford, UK, 2003; pp. 121-159.

15. Ræbild, A.; Hansen, U.B.; Kambou, S. Regeneration of Vitellaria paradoxa and Parkia biglobosa in a parkland in Southern Burkina Faso. Agrofor. Syst. 2012, 85, 443-453.

16. Darkoh, M.B.K. Regional perspectives on agriculture and biodiversity in the drylands of Africa. J. Arid Environ. 2003, 54, 261-279.

17. Chubey, M.S.; Franklin, S.E.; Wulder, M.A. Object-based analysis of IKONOS-2 imagery for extraction of forest inventory parameters. Photogramm. Eng. Remote Sens. 2006, 72, 383-394.

18. DeFries, R.; Achard, F.; Brown, S.; Herold, M.; Murdiyarso, D.; Schlamadinger, B.; de Souza, C., Jr. Earth observations for estimating greenhouse gas emissions from deforestation in developing countries. Environ. Sci. Policy 2007, 10, 385-394.

19. Falkowski, M.J.; Wulder, M.A.; White, J.C.; Gillis, M.D. Supporting large-area, sample based forest inventories with very high spatial resolution satellite imagery. Prog. Phys. Geogr. 2009, 33, 403-243.

20. Leckie, D.G.; Gougeon, F.A.; Tinis, S.; Nelson, T.; Burnett, C.N.; Paradina, D. Automated tree recognition in old growth conifer stands with high resolution digital imagery. Remote Sens. Environ. 2005, 94, 311-326.

21. Rasmussen, M.O.; Göttesche, F.M.; Diop, D.; Mbow, C.; Olesen, F.S.; Fensholt, R.; Sandholt, I. Tree survey and allometric models for tiger bush in northern Senegal and comparison with tree parameters derived from high resolution satellite data. Int. J. Appl. Earth Observ. Geoinf. 2011, $13,517-527$.

22. Kuyah, S.; Muthuri, C.; Jamnadass, R.; Mwangi, P.; Neufeldt, H.; Dietz. J. Crown area allometries for estimation of aboveground tree biomass in agricultural landscapes of western Kenya. Agrofor. Syst. 2012, 86, 267-277.

23. Hirata, Y.; Tabuchi, R.; Patanaponpaiboon, P.; Poungparn, S.; Yoneda, R.; Fujioka, Y. Estimation of aboveground biomass in mangrove forests using high-resolution satellite data. J. For. Res. 2014, 19, 34-41. 
24. Colgan, M.S.; Baldeck, C.A.; Féret, J.-B.; Asner, G.P. Mapping savanna tree species at ecosystem scales using support vector machine classification and BRDF correction on airborne hyperspectral and LiDAR data. Remote Sens. 2012, 4, 3462-3480.

25. Chávez, R.O.; Clevers, J.G.P.W.; Herold, M.; Acevedo, E.; Ortiz, M. Assessing water stress of desert tamarugo trees using in situ data and very high spatial resolution remote sensing. Remote Sens. 2013, 5, 5064-5088.

26. Immitzer, M.; Atzberger, C.; Koukal, T. Tree species classification with random forest using very high spatial resolution 8-band WorldView-2 satellite data. Remote Sens. 2012, 4, 2661-2693.

27. Lucas, R.; Bunting, P.; Paterson, M.; Chrisholm, L. Classification of Australian forest communities using aerial photography, CASI and HyMap data. Remote Sens. Environ. 2008, 112, 2088-2103

28. Cho, M.A.; Mathieu, R.; Asner, G.P.; Naidoo, L.; van Aardt, J.; Ramoelo, A.; Debba, P.; Wessels, K.; Main, R.; Smit, I.P.J.; et al. Mapping tree species composition in South African savannas using an integrated airborne spectral and LiDAR system. Remote Sens. Environ. 2012, 125, 214-226.

29. Féret, J.B.; Asner, G.P. Tree species discrimination in tropical forests using airborne imaging spectroscopy. IEEE Trans. Geosci. Remote Sens. 2013, 51, 73-84.

30. Romijn, E.; Herold, M.; Kooistra, L.; Murdiyarso, D.; Verchot, L. Assessing capacities of non-Annex I countries for national forest monitoring in the context of REDD+. Environ. Sci. Policy 2012, 19-20, 33-48.

31. Asner, G.P.; Palace, M.; Keller, M.; Pereira, R., Jr.; Silva, J.N.M.; Zweede, J.C. Estimating canopy structure in an Amazon forest from laser range finder and IKONOS satellite observations. Biotropica 2002, 34, 483-492.

32. Read, J.M.; Clark, D.B.; Venticinque, E.M.; Moreira, M.P. Application of 1-m and 4-m resolution satellite data to research and management in tropical forests. J. Appl. Ecol. 2003, 40, 592-600.

33. Clark, D.B.; Read, J.M.; Clark, M.; Cruz, A.M.; Dotti, M.F.; Clark, D.A. Application of 1-m and 4-m resolution satellite data to studies of tree demography, stand structure and land use classification in tropical rain forest landscapes. Ecol. Appl. 2004, 14, 61-67.

34. Ke, Y.; Quackenbush, L.J. A review of methods for automatic individual tree-crown detection and delineation from passive remote sensing. Int. J. Remote Sens. 2011, 32, 4725-4747.

35. Nagendra, H.; Rocchini, D. High resolution satellite imagery for tropical biodiversity studies: The devil is in the detail. Biodivers. Conserv. 2008, 17, 3431-3442.

36. Nagendra, H.; Rocchini, D.; Ghate, R.; Sharma, B.; Pareeth, S. Assessing plant diversity in a dry tropical forest: Comparing the utility of Landsat and IKONOS satellite images. Remote Sens. 2010, 2, 478-496.

37. Karlsson, M.; Ostwald, M. Linköping University, Linköping, Sweden. Unpublished work, 2014.

38. Wulder, M.; Niemann, K.O.; Goodenough, D.G. Local maximum filtering for the extraction of tree locations and basal area from high spatial resolution imagery. Remote Sens. Environ. 2000, $73,103-114$.

39. Pitkänen, J. Individual tree detection in digital aerial images by combining locally adaptive binarization and local maxima methods. Can. J. For. Res. 2001, 31, 832-844. 
40. Pollock, R.J. The Automatic Recognition of Individual Trees in Aerial Images of Forests Based on a Synthetic Tree Crown Model. PhD Thesis, University of British Columbia, Vancouver, Canada, 1996.

41. Culvenor, D.S. TIDA: An algorithm for the delineation of TCs in high spatial resolution remotely sensed imagery. Comput. Geosci. 2002, 28, 33-44.

42. Gougeon, F.A. A crown-following approach to the automatic delineation of individual TCs in high spatial resolution aerial images. Can. J. Remote Sens. 1995, 21,274-284.

43. Wang, L.; Gong, P.; Biging, G.S. Individual tree-crown delineation and treetop detection in high-spatial-resolution aerial imagery. Photogramm. Eng. Remote Sens. 2004, 70, 351-357.

44. Bunting, P.; Lucas, R. The delineation of tree crowns in Australian mixed species forests using hyperspectral Compact Airborne Spectrographic Imager (CASI) data. Remote Sens. Environ. 2006, 101, 230-248.

45. Gougeon, F.A.; Leckie, D.G. The individual tree crown approach applied to IKONOS images of a coniferous plantation area. Photogramm. Eng. Remote Sens. 2006, 72, 1287-1297.

46. Asner, G.P.; Wessman, C.A.; Schimel, D.S. Heterogeneity of savanna canopy structure and function from imaging spectrometry and inverse modeling. Ecol. Appl. 1998, 8, 1022-1036.

47. Hoffman, W.A.; da Silva, E.R.; Machado, G.C.; Bucci, S.J.; Scholtz, F.G.; Goldstein, G.; Meinzer, F.C. Seasonal leaf dynamics across a tree density gradient in a Brazilian savanna. Oecologica 2005, 145, 306-315.

48. Ardila, J.P.; Bijker, W.; Topekin, V.A.; Sten, A. Context-sensitive extraction of tree crown objects in urban areas using VHR satellite images. Int. J. Appl. Earth Observ. Geoinf. 2012, 15, $57-69$.

49. Blaschke, T. Object based image analysis for remote sensing. ISPRS J. Photogramm. Remote Sens. 2010, 65, 2-16.

50. Baatz, M.; Schäpe, A. Multiresolution segmentation: An optimization approach for high quality multi-scale image segmentation. In Angewandte Geographische Informationsverarbeitung, 7th ed.; Strobl, J., Griesebner, G., Eds.; Herbert Wichmann Verlag: Heidelberg, Germany, 2000; pp. 12-23.

51. Benz, U.C.; Hofmann, P.; Willhauck, G.; Lingenfelder, I.; Heynen, M. Multi-resolution, object-oriented fuzzy analysis of remote sensing data for GIS-ready information. ISPRS J. Photogramm. Remote Sens. 2004, 58, 239-258.

52. Hay, G.J.; Castilla, G. Geographic object-based image analysis (GEOBIA): A new name for a new discipline. In Object Based Image Analysis, 1st ed.; Springer: Berlin/Heidelberg, Germany, 2008; pp. 75-89.

53. Strahler, A.H.; Woodcock, C.E.; Smith, J.A. On the nature of models in remote sensing. Remote Sens. Environ. 1986, 20, 121-139.

54. Gibbes, C.; Adhikari, S.; Rostant, L.; Southworth, J.; Qiu, Y. Application of Object Based Classification and High Resolution Satellite Imagery for Savanna Ecosystem Analysis. Remote Sens. 2010, 2, 2748-2772.

55. Boggs, G.S. Assessment of SPOT 5 and Quickbird remotely sensed imagery for mapping tree cover in savannas. Int. J. Appl. Earth Observ. Geoinf. 2010, 12, 217-224. 
56. Peel, M.C.; Finlayson, B.L.; McMahon, T.A. Updated world map of the Köppen-Geiger climate classification. Hydrol. Earth Syst. Sci. 2007, 11, 1633-1644.

57. Jonsson, K.; Ong, C.K.; Odongo, J.C.W. Influence of scattered nere and karite trees on microclimate, soil fertility and millet yield in Burkina Faso. Exp. Agric. 1999, 35, 39-53.

58. Le Houerou, H.N. The Grazing Land Ecosystems of the African Sahel, 1st ed.; Springer: New York, NY, USA, 1989; p. 282.

59. Arbonnier, M. Trees, Shrubs and Lianas of West African Dry Zones, 2nd ed.; Margaf Publishers: Paris, France, 2004; p. 573.

60. Updike, T.; Comp, C. Radiometric Use of WorldView-2 Imagery. In Technical Note; Digital Globe: Longmont, CO, USA, 2010; pp. 1-17.

61. Padwick, C.; Deskevich, M.; Pacifici, F.; Smallwood, S. WorldView-2 Pan-Sharpening. In Proceedings of the ASPRS 2010 Annual Conference, San Diego, CA, USA, 26-30 April 2010.

62. Rouse, J.W.; Hass, R.H.; Schell, J.A.; Deering, D. Monitoring vegetation systems in the great plains with ERTS. NASA Special Publication 1974, 351, 309-317.

63. Lam, T.Y.; Kleinn, C.; Coenradie, B. Double sampling for stratification for the monitoring of sparse tree populations: The example of Populus euphratica Oliv. forests at the lower reaches of Tarim River, Southern Xinjiang, China. Environ. Monit. Assess. 2011, 175, 45-61.

64. Mueller-Dombois, D.; Ellenberg, H. Aims and Methods of Vegetation Ecology, 1st ed.; the Blackburne Press: New York, NY, USA, 1974; p. 547.

65. Trimble. eCognition Developer Reference Book; Trimble: Munich, Germany, 2012; p. 423.

66. Huete, A.; Justice, C.; Liu, H. Development of vegetation and soil indices for MODIS-EOS. Remote Sens. Environ. 1994, 49, 224-234.

67. Ball, G.H.; Hall, D.J. Isodata: A novel method of data analysis and pattern classification. In Technical Report; Stanford Research Institute: Menlo Park, CA, USA, 1965; pp. 1-60.

68. Dougherty, E.R. Mathematical Morphology in Image Processing, 1st ed.; CRC Press: New York, NY, USA, 1993; p. 552.

69. Pouliot, D.A.; King, D.J.; Bell, F.W.; Pitt, D.G. Automated tree crown detection and delineation in high-resolution digital camera imagery of coniferous forest regeneration. Remote Sens. Environ. 2002, 82, 322-334.

70. Willmot, C.J.; Matsuura, K. Advantages of the mean absolute error (MAE) over the root mean square error (RMSE) in assessing average model performance. Clim. Res. 2005, 30, 79-82.

71. Laliberte, A.; Fredrickson, E.; Rango, A. Combining decision trees with hierarchical object-oriented image analysis for mapping arid rangelands. Photogramm. Eng. Remote Sens. 2007, 73, 197-207.

72. Straub, C.; Tian, J.; Seitz, R.; Reinartz, P. Assessment of Cartosat-1 and WorldView-2 stereo imagery in combination with a LiDAR-DTM for timber volume estimation in a highly structured forest in Germany. Forestry 2013, 86, 463-473.

73. Brandtberg, T.; Walter, F. Automated delineation of individual tree crowns in high spatial resolution aerial images by multiple-scale analysis. Mach. Vis. Appl. 1998, 11, 64-73.

74. Morales, M.; Miura, T.; Idol, T. An assessment of Hawaiin dry forest condition with fine resolution remote sensing. For. Ecol. Manag. 2008, 7, 2524-2532. 
75. Scanlon, T.M.; Caylor, K.K.; Levin, S.A.; Rodriguez-Iturbe, I. Positive feedbacks promote power-law clustering of Kalahari vegetation. Nature 2007, 449, 209-212.

76. Wu, J.; Loucks, O. From balance of nature to hierarchical patch dynamics: A paradigm shift in ecology. Quart. Rev. Biol. 1995, 70, 439-466.

77. Herrmann, S.M.; Wickhorst, A.J.; Marsh, S.E. Estimation of tree cover in an agricultural parkland of Senegal using rule-based regression tree modeling. Remote Sens. 2014, 5, 4900-4918.

(C) 2014 by the authors; licensee MDPI, Basel, Switzerland. This article is an open access article distributed under the terms and conditions of the Creative Commons Attribution license (http://creativecommons.org/licenses/by/4.0/). 